\title{
Correction to: Extracting Shoreline from Satellite Imagery for GIS Analysis
}

\author{
Debabrata Ghorai $^{1}$ (D) $\cdot$ Manik Mahapatra $^{2}$
}

Published online: 20 January 2020

(C) Springer Nature Switzerland AG 2020

\section{Correction to: Remote Sens Earth Syst Sci.}

https://doi.org/10.1007/s41976-019-00030-w

The original version of this article unfortunately contained some mistakes. At Section 2.3 Image Classification, the following sentences are technically not correct.

Sentence 1: If the binary image has floating point, then.......other related program.

Sentence 2: To reduce the number of iterations.....256 gray levels.

These should be replaced by "Therefore, the image pixel values were normalized and stretched to 256 gray levels".

The original article has been corrected.

The online version of the original article can be found at https://doi.org/ 10.1007/s41976-019-00030-w

Debabrata Ghorai

Paschim Medinipur, India

2 National Centre for Sustainable Coastal Management, Ministry of Environment, Forest and Climate Change, Anna University Campus, Chennai, Tamil Nadu, India 